\title{
Natural Methods to Assist Delivery during the Second Stage of Labour: Part I: Positioning and the Role of Intrapartum Ultrasound
}

\section{Maria Papamichail, Panos Antsaklis, Marianna Theodora, Michael Syndos, George Daskalakis, Dimitrios Loutradis}

$1^{\text {st }}$ Department of Obstetrics and Gynecology, "Alexandra" Hospital, National and Kapodistrian University of Athens, Greece

Corresponding Author

Maria Papamichail, Medical Doctor - University of Athens, e-mail: mapapam@hotmail.com

\section{Abstract}

Labour has high importance for every woman's life but also is the moment when many complications might appear increasing significantly morbidity and mortality. Therefore obstetricians have to help women in labour to give birth to their babies naturally, with the highest satisfaction possible. Western standards suggest that women should experience their partirution in the lithotomy or the supine position. However, upright positions have the potential to reduce second stage of labour and to improve neonatal outcomes. Intrapartum ultrasound using different parameters can predict the remaining time to delivery and therefore to make timely interventions in order to decrease instrumental or caesarean deliveries and postpartum hemorrhage as these are the most important complications met in prolonged second stage of labour. In this review the optimal positioning of the women in labour will be presented. Additionally, the ability of intrapartum to shorting second stage duration and to increase maternal satisfaction concerning childbirth will also mentioned.

\section{Introduction}

According to WHO, 140 million of births occur annually all around the world. ${ }^{1}$ The vast majority of these births are supervene in women without risk factors neither for the women in labour, nor for their babies. Nevertheless, labour is a period of time that carries great importance, as is the time where the morbidity and mortality of both the mother and her unborn baby might increase significantly, if complications appear.

We made an attempt to provide evidence-based information about how the health care providers can assist the woman in labour, in order to help both the mother and her unborn child to experience labour and delivery positively, with the least possible interventions and adverse effects short and long-term. In this, first part of the article, we will present an 
overview of the optimal positioning of the women in labour. In addition, intrapartum ultrasound and its role for predicting delivery time, shorting duration of the second stage of labour or increasing maternal satisfaction concerning childbirth will be reviwed. Finally, mother's immediate pospartum connection with the newborn will be also mentioned.

\section{Positioning}

\section{Background}

The vast majority of women worldwide are positioned in the lithotomy position during the second stage of labour ${ }^{2}$ and according to Rossi et $\mathrm{al}^{3}$ this might be due to cultural norms, as even in nonprescriptive environments women choose giving birth in bed. But when Engelmann observed women in labour back in 1882, stated the opposite: he claimed that if women were not influenced by Western standards, they would prefer changing positions instead of the classic dorsal position ${ }^{4}$. Hodnett and Rooks mentioned that when a woman in parturition is mobilized or changing positions, she has better control of the childbirth procedure, and this might decrease the sense of pain and therefore her need for analgesia ${ }^{5,6}$. Interestingly, Korokawa and Ramond noted that squatting is the most frequently position chosen by women who are free to decide which position they would adopt during labour ${ }^{7,8}$. A significant percentage of obstetricians and midwives agree that when the mother is positioned in bed during labour, makes the provision of care safer, as they can make any intervention such as intavenus fluids, regional anesthesia or the digital vaginal examination, easier, and they also can monitor the fetus's heart rate patterns more efficiently. As a result, health care providers have greater control of the whole procedure. Nevertheless, supine positions during labour has been accused for adverse effects in hemodynamic measures for the mother, infant and newborn, ${ }^{9,10}$ and thus, upright positions such as walking, standing, sitting, squatting and kneeling ${ }^{11}$ have been recommended as better.

\section{Defining the different position in labour}

This is a good opportunity for giving the definitions of the supine positions: Supine position is the state where the mother is lying in her back. Supine positions include the dorsal position where the woman lies totally on her back, the lateral position where the woman is lying on her side, more frequently in the left side in order to eliminate compression to the inferior vena cava resulting free blood flow to the right atrium and therefore better hemodynamic outcomes, the semi-recumbent position where the woman is angled partly upright and the lithotomy position where the woman's legs are held up in stirrups.

\section{Literature Review}

A Cochrane analysis which took place in $2017^{12}$ and both primiparus and multiparus women without epidural analgesia were included, concluded that upright positions can reduce slightly the duration of the second stage of labour (MD, -6.16 minutes; $95 \%$ CI $-9.74-2.59$ minutes, $\mathrm{P}=0.0007$ ) - in this survey the duration of the second stage of labour was identical with the time of pushing, as the women were directed to push immediately after full cervical dilatation. This reduction of second stage duration is mainly due to the group of women who chosen a birth cushion as in this position, the reduction was greater. In addition, the possibility of an instrumental vaginal delivery was also decreased (RR, 0.75; 95\% CI, 0.66-0.86) as far as episiotomy rates (RR, $0.75 ; 95 \% \mathrm{CI}, 0.61-0.92$ ). The possibility of a caesarean section did not differ between the women who adopted neither a supine nor an upright position (RR 1.22, 95\% CI 0.81 to 1.81). Two other maternal outcomes which statistical significance was not presented is the possibility of manual removal of placenta (RR 0.75, 95\%CI 0.02-25.79) and shoulder 2 
dystocia (RR 0.20, 95\% CI 0.01-4.11). As far as the neonatal outcomes are concerned, fetuses whom their mother was having an upright position were less likely to present an abnormal heart rate pattern (RR $0.46,95 \%$ CI 0.22 to 0.93 ), although the need for admission to a neonatal care unit was not different between the two groups (RR $0.79,95 \%$ CI 0.51 - 1.21). Nevertheless, upright positions were associated with two adverse effects considering the maternal outcomes: estimated blood loss greater than $500 \mathrm{ml}$, occurred more frequently in women who were positioned uprightly (RR 1.48, 95\% CI $1.10-1.98)$ and there was also a greater possibility of second degree perineal tears (RR 1.20, 95\% CI 1.00 - 1.44). However, there was no clear difference for the possibility of third or fourth grade perineal lacerations (RR 0.72, 95\% CI 0.32 - 1.65), or the need for blood transfusion (RR 2.02, 95\% CI 0.18 - 22.18).

A different analysis that occurred four years earlier ${ }^{11}$, provided evidence that was partly aligned with the Cochrane Analysis above. The major disagreements were that when women was grouped in two arms: the first included women in upright and ambulant positions and the second arm included women in recumbent positions and bed care, the reduction of the second stage of labour was much greater than the 2017 analysis, as the time of pushing was shorter for one hour and 22 minutes (82 minutes- MD -1.36, 95\% CI -2.22 - -0.51), and both nuliparus and multiparus women were included to the analysis. The reduction was even greater in the nuliparus sub-group. Other dissents is that in women who were positioned uprightly, caesarean sections was statistical significantly fewer (RR 0.71, $95 \%$ CI 0.54 to 0.94 ), the possibility of epidural analgesia was smaller (RR $0.81,95 \%$ CI 0.66 to 0.99 ), and their infants were less likely to be transmitted to a neonatal intensive care unit (RR $0.20,95 \% \mathrm{CI}$ 0.04 to 0.89 ).

\section{The effects of epidural analgesia}

It is well known that epidural analgesia might increase the total time of labour and therefore the possibility for an operative delivery when vacuum, forceps and caesarean section are included to the definition. Moreover, due to the prolonged labour, newborns are more likely to present low cord $\mathrm{pH}$, low Apgar scores, or increased possibility to be transmitted to an intensive care unit. ${ }^{13}$ Pathophysiologically, the increased duration of labour in women with epidural analgesia can be explained because the release of oxytocin might be intervened and being reduced as long as because the mother's bearing down reflex is inhibited ${ }^{14,15}$. In addition, several upright positions which are studied in surveys including women without epidural analgesia, may be difficult to be achieved by women with this type of pain relief. As a result, this group of women has to be studied individually. When women with epidural analgesia were taken into consideration ${ }^{16}$, authors couldn't reach a conclusive result because of the low quality of the existing trials including women with epidural analgesia. They found no statistical significant differences between women who were positioned neither in upright nor a supine position concerning many maternal or neonatal outcomes. They had investigated the operative births including instrumental vaginal deliveries and caesarian sections, the duration of the second stage of labour, perineal lacerations requiring suturing, abnormal fetal heart rate patterns where an intervention was needed, low cord $\mathrm{pH}$ and admission to neonatal intensive care and they failed to find any statistical significant relation. However, authors suggest position changes during childbirth for women with epidural analgesia, as a sustained position, either upright or supine, is associated with lumbosacral spine and lower extremity nerve injuries. In addition, avoidance of exaggerated flexion of the legs is encouraged, as it might prevent postpartum neurological injuries ${ }^{17}$. 


\subsection{Pathophysiologic Explanation}

When women are experiencing parturition uprightly, the pelvis is able to expand as the fetus descents into the birth canal. This downward movement is also assisted by gravity, as in an upright position the heavy and large uterus does not press the major vessels of the mother, leading to unbearable oxygen and nutrition supply to the fetus, improving its acid-base outcomes. ${ }^{12,18-19}$ Moreover, in a kneeling or a squatting position, uterine contractions are stronger and more efficient in means of frequency and regularity ${ }^{11}$, the fetus takes a better position helping it to pass through the birth canal ${ }^{20-28}$, and this occurs, mainly due to both factors discussed above. Interestingly, postural alterations during labour have been associated with better outcomes concerning fetal head malposition or acynclitism ${ }^{29}$. The increased possibility of second degree perineal tears can be explained by this fact: as it is mentioned, an upright position which a significant percentage of women choose is the squatting position. Although, the vast majority of Western women do not have the necessary muscle strength and the balance required to remain squatted for a long period of time, leading to increasing numbers of second degree perineal lacerations ${ }^{24}$.

\subsection{Maternal Satisfaction}

When women are asked to describe their childbirth experience in an upright position, they comment that giving birth uprightly becomes easier and in contrast, when a supine position is chosen, childbirth is described as painful, difficult and uncomfortable. As a result it is recommended by $\mathrm{WHO}$ and physicians that every woman should be free to decide the position or mobile state which is ideal for her, wand it carries the less pain and discomfort, and they mention that an upright position can be suggested. Therefore, women would experience parturition better and more positively. ${ }^{1,11,12}$
The role of intrapartum ultrasound

\section{Predicting the remaining time to delivery}

The ability of predicting the remaining time to delivery is a major benefit for obstetricians as a prolonged second stage of labour can carry multiple adverse effects for the mother, such as a higher possibility of instrumental vaginal delivery, perineal trauma, postpartum hemorrhage and chorioamnionitis ${ }^{31-32}$. In addition, not only the frequency or duration of the uterine contractions, but also their intensity is equally significant for prognosticating the time to delivery. Thus, several methods had been used as predicting factors for estimating the delivery timing. Firstly, digital vaginal examination has been established as the traditional technique for evaluating cervical dilatation, fetal descent and fetal head rotation, despite the evidence suggesting its limited accuracy and reproducibility ${ }^{33-34}$. Secondly, external tocodynamometry was used for detecting the strength and frequency of the uterine contractions, but its prognostic ability in a situation of an increased maternal body mass index (BMI) is eliminated ${ }^{35-36}$. IntraUterine Pressure Catheter (IUPC) was the third method which was introduced for assessing the efficiency of the uterine contractions ${ }^{35}$. However, IUPC has been blamed for uterine perforation, placental abruption and endometritis ${ }^{37-43}$, and it has no impact for any overall maternal or fetal outcome ${ }^{4-45}$. Finally, an innovative technique which is gaining popularity among the obstetric community, is the transperineal ultrasound during the second stage of labour- or transperineal intrapartum ultrasound ${ }^{33}$. This method in non-invasive, with high reproducibility and the progress of the fetal head rotation can be clearly visualized $^{46}$.

The usage of intrapartum ultrasound is greatly beneficial, as if the second stage of labour is seems to be prolonged, a timely obstetrician intervention ${ }^{47}$ is more than necessary for preventing any of the complication which have been mentioned 
above. Morever, a prediction of the delivering time is advantageous when the labour has to accelerate because of a possible abnormal fetal heart rate or a maternal cardiac disease ${ }^{52}$.

Additionally, many authors, including Yonetani et $\mathrm{al}^{33}$ and Ghi et $\mathrm{al}^{52}$ provided evidence suggesting that intrapartum ultrasound can estimate more accurately and with higher reproducibility the remaining time to delivery, compared to the digital vaginal examination, especially in nulliparous women. This is mainly due to the fact that the intrapartum ultrasound is not affected by the increasing caput succedaneum and deformity of the fetal skull, which are two variables that affects greatly the digital vaginal examination.

Several ultrasound parameters and their capability for predicting the remaining time to delivery have been evaluated and they are presented in Table 1 . Nevertheless, many articles in the existing literature argue that the most reliable measure in order to detect more accurately the time to delivery is AoP, which reflects the fetal head descent ${ }^{50-51}$. MLA is the factor that can predict the fetal head rotation. As far as the reproducibility is concerned, MLA and AoP had the highest values among the other ultrasound findings which were studied by Yonetani et $\mathrm{al}^{33}$, with AoP recording a 0.87 intraclass correlation coefficients and MLA 0.82 for the same observer and 0.75 and 0.27 for two observers, respectively.
Yonetani et $\mathrm{al}^{33}$ ran a clinical trial assessing the relationship between time to delivery, AoP and MLA in nulliparous and multiparous women. They found that these two ultrasound measures are significantly associated with the remaining time to delivery in both groups. More specifically, the time to delivery is shorten as the AoP is increasing and MLA is decreasing. Speaking with numbers, for nulliparous women a AoP $\geq 160^{\circ}$ was significantly $(\mathrm{P}<0.05)$ related with the time to delivery, as the $93 \%$ of the women with an $\mathrm{AoP} \geq 160^{\circ}$ delivered within 2 hours. Regarding MLA, nulliparous women with a measure of an MLA $<10^{\circ}$ were $92 \%$ likely to deliver within 2 hours. For the multiparous women these numbers were for AoP $\geq 150^{\circ}$ ( $92 \%$ possibility for delivery within 2 hours) and MLA $<10^{\circ}(90 \%$ possibility for delivery within 2 hours $-\mathrm{P}<0.05$ ).

Ghi et $\mathrm{al}^{52}$ in their study, came to an agreement with Yonetani et al and Brocera et $\mathrm{al}^{53}$ regarding the smaller AoP $(\mathrm{P}<0.001)$ and the shorter duration of labour. However, they did not find any relation with MLA. Conversely, they had also investigated PD $(\mathrm{P}=0.008)$, which was smaller and HSD $(\mathrm{P}<0.001)$, which was greater in early delivery. Early delivery was defined as delivery within 60 minutes starting from the active second stage of labour. Additionally, they assessed these four measures at the beginning of the active second stage (T1) and in 240 -minute

Table 1. Ultrasound parameters for remaining time to delivery predection.

\begin{tabular}{|c|c|}
\hline ULTRASOUND FINDING & DEFINITION \\
\hline Angle of progression (AoP) & $\begin{array}{l}\text { The angle between a line through the long axis of the pubic bone and a line from the } \\
\text { anterior edge of the pubis to the leading edge of the fetal head in the maternal midsaggital } \\
\text { position }{ }^{67,69}\end{array}$ \\
\hline$\triangle \mathrm{AoP}$ & The difference between the AoP measured in a concractile and a non-concractile period 69 . \\
\hline Midline Angle (MLA) & $\begin{array}{l}\text { The angle between the fetal head midline and the anteroposterior axis of the maternal pelvis } \\
\text { in a transverse section }{ }^{67}\end{array}$ \\
\hline Progression Distance (PD) & The distance between the infrapubic line and the lowest part of the fetal skull ${ }^{82}$ \\
\hline Head-Symphysis Distance (HSD) & $\begin{array}{l}\text { The distance between the lowest edge of the symphysis pubis and the nearest point } \\
\text { of the fetal skull along the infrapubic line } e^{83}\end{array}$ \\
\hline
\end{tabular}


intervals (T2, T3) until delivery, and they found that these measures were statistically significant only for T1. More specifically, when the HSD is greater than $20 \mathrm{~mm}$ as soon as the active second stage begins, the possibility of a late delivery is getting higher.

Muramoto et $\mathrm{al}^{35}$ also reached to similar conclusions in their study which took place in 2016. The AoP was found to be significantly associated with the remaining time to delivery in nulliparous women $(139.3 \pm 3.8$ for $\leq 50$ min vs. $130.2 \pm 1.9$ for $>50 \mathrm{~min}$; $\mathrm{P}=0.046$ ), while for multiparous this difference was not statistically significant $(135.8 \pm 6.2$ for $\leq 20 \mathrm{~min}$ vs. $128.5 \pm 3.2$ for $>20 \mathrm{~min}$; $\mathrm{P}=0.37$ ). When the AoP was greater than $131^{\circ}$, there is $75 \%$ possibility of a spontaneous vaginal delivery within 50 minutes. They had also assessed the difference of the angle of progression during a contraction and the AoP in a non-concractile period ( $\triangle \mathrm{AoP})$. They found that for nulliparous women, the greater the $\Delta \mathrm{AoP}$, the shorter the second stage of labour $(52.5 \pm 5.0$ for $\leq 50 \mathrm{~min}$ vs. $30.9 \pm 2.1$ for $>50 \mathrm{~min} ; \mathrm{P}=0.001$ ). In multiparous women, although $\triangle \mathrm{AoP}$ followed the same trends, it was not statistically significant $(43.0 \pm 4.3$ for $\leq 20$ min vs. $33.5 \pm 5.5$ for $>20 \mathrm{~min}$; $\mathrm{P}=0.18$ ). In addition, when $\triangle \mathrm{AoP}$ was greater than $40^{\circ}$, there was $85 \%$ possibility of a spontaneous vaginal delivery within 50 minutes.

\section{Diagnosing a permanent occiput posterior position}

In addition, Ghi et al ${ }^{54}$ assessed the capability of the intrapartum ultrasound of diagnosing the permanent fetal occiput posterior (OP) position. This knowledge is also greatly beneficial for obstetricians, as fetuses positioned posteriorly have greater possibility for dystocia and other complications (higher possibilities for Caesarean Section and ineffective instrumental vaginal delivery), requiring timely interventions. The authors grouped the fetuses according to their position (anterior vs posterior) and they compared their sonographic measures (AoP, HSD, HD, PD and MLA). They found that fetuses with an occiput posterior position presented a significantly smaller AoP (122 \pm $17 \circ$ vs $\left.138 \pm 20^{\circ}, P=0.016\right)$, while HSD $(16.5 \pm 5.4 \mathrm{~mm}$ vs $22.8 \pm 6.6 \mathrm{~mm}, P=0.008$ ) and HD were significantly higher $(112 \pm 17 \mathrm{~mm}$ vs $86 \pm 19 \mathrm{~mm}, P<0.001)$ when they were measured at the beginning of the second stage of labour and 40 minutes afterwards. A statistically significant difference was not recorded regarding $P D$ and MLA. A smaller AoP and a greater HSD are presented, because a fetus that is positioned posteriorly follows a downward direction until the forehead has passed the pubic bone, demanding a higher-degree flexion. Conversely, the internal rotation and depth of the posteriorly-positioned fetuses are similar to the anteriorly-positioned ones, leading to similar MLA and $\mathrm{PC}$, respectively.

\section{VISUAL BIOFEEDBACK}

Intrapartum ultrasound is not only usefull for predicting the remaining time to delivery or diagnosing an occiput posterior position. Two recent trials (Gilboa et $\mathrm{al}^{54}-2017$ and Belluci et $\mathrm{al}^{46}$-2018) suggested that the visualization of the progress of the fetal head using a real-time ultrasound - called otherwise "visual biofeedback" has the potential of increasing the efficiency of the bearing down efforts. Biofeedback can be defined as: the process of getting a deeper understanding of a physiological function of our body, by using methods and instruments which provide information about a specific systemic activity, aiming to gain the ability to improve $i t^{55}$.

The first method that was been used in order to improve the efficiency of the bearing down efforts of the parturients, was called "the mirror technique"56. In this method, the woman was placed in front of a mirror and she was able to watch the effects of her pushing efforts on her baby's head revelation. However, when an ultrasound screen is used in order to provide the parturient the information about the fetal 
head status, several advantages are presented: firstly, the procedure can take place before the presence of the fetal head in the introtius and secondly, the effort can be translated into a measure of a greater angle of progression.

More specifically, when visual biofeedback via an ultrasound screen, is being used in the labour procedure, it can help parturients with epidural analgesia to push more efficiently, to reduce the possibility of perineal trauma and to feel a stronger connection to the newborn, shortly after delivery. These advantages are mainly due to the potential of the biofeedback of offering to the woman in labour information about her clinical status, the opportunity to change it, and therefore the ability to improve her labour performance. Additionally, the motivation given is considerable increased. Finally, the parturient might feel that she has control of her body and that she has an active role in the whole procedure of delivery.

The visual biofeedback, in order to reveal its positive effects has to be explained to the woman and frequently this illustration is not longer than 5 minutes, it is easy to be understood and its great capability to improve the labour performance makes it cost-effective. The team responsible for the management of the woman's labour, explains briefly on the ultrasound screen the intrapartum ultrasound method and its association of the fetal head and its direction through the birth canal. Afterwards, simple movements which have the ability to move the fetal head, such as cough and the Valsalva effect, are asked to be performed by the mother, in order to understand the movement of her baby's head. Finally, when a uterine contraction is present, the parturient watches the movement of the fetal head towards the birth canal, providing her a clear biofeedback of the efficacy of her bearing down efforts on the ultrasound screen. In addition, the team encouraged the mother to visualize mentally the progress of the fetal head descent until delivery.
The outcomes of Gilboa et al study were really interesting. The pushing efforts improved significantly after the biofeedback intervention $(\mathrm{P}=0.01), \Delta \mathrm{AoP}$ was significantly lower (and this reflects a better fetal descent through the birth canal), the possibility of perineal trauma was reduced by $11.1 \%$ and mothers felt a stronger connection to their baby. The non-statistically significant outcomes were the length of the second stage of labour, the maternal feelings of control and satisfaction with childbirth.

Bellussi et al, in contrast with Gilboa et al, found a statistically significant decrease of the active second stage of labour (MD 15 minutes, $\mathrm{p}=0.01$ ), and this is equivalent with a $20 \%$ reduction of the duration of the active second stage. Regarding the AoP, it was greatly increased during the first 20 minutes of coaching (MD: 8,5, $\mathrm{p}=0.01$ ).

\section{Conclusion}

In conclusion, partirution has significant importance in every woman's life and has to be experienced with the highest satisfaction possible. This can be achieved by offering the woman the opportunity to choose by herself the ideal position in which she will give birth to her child. Additionally, modern literature suggests that intrapartum ultrasound has the potential to reduce the second stage of labour duration and to increase significantly maternal satisfaction and the immediate connection to the newborn. Despite the innovative findings of these trials run since now, they had small samples and their methodology can be improved. Therefore, further research is necessary in order to define the effectiveness of visual biofeedback and thereofre to be established in obstetric daily routine.

\section{References}

1. WHO recommendations: intrapartum care for a positive childbirth experience. ISBN 978-92-4-155021-5 
2. Roberts J, Hanson L. Best Practices in Second Stage Labor Care: Maternal Bearing Down and Positioning American College of Nurse-Midwives, 2007; 1526-9523/07

3. Rossi MA, Lindell SG. Maternal positions in a nonprescriptive environment. J Obstet Gynecol Neonatal Nurs 1986;15:203-8.

4. Engelmann GJ. Labor Among Primitive Peoples. St. Louis:JH Chambers, 1882.

5. Hodnett ED, Gates S, Hofmeyr GJ, Sakala C. Continuous support for women during childbirth. Cochrane Database of Systematic Reviews 2012, Issue 10. [DOI: 10.1002/ 14651858.CD003766.pub4

6. Rooks JP. Evidence-based practice and its application to childbirth care for low-risk women. Journal of Nurse Midwifery 1999;44(4):355-69.

7. Kurokawa J, Zilkoski MW. Adapting hospital obstetrics to birth in the squatting position. Birth 1985;12(2):87-90.

8. Romond JL, Baker IT. Squatting in childbirth. A new look at an old tradition. Journal of Obstetric, Gynecologic, and Neonatal Nursing 1985;14(5):406-11.

9. Sleep J, Roberts J, Chalmers I. Care during the second-stage of labour. In: Enkin M, Keirse MJNC, Neilson J, Crowther C, Duley L, Hodnett E, et al, editors. A guide to effective care in pregnancy and childbirth. New York: Oxford University Press,2000. pp. 290-8.

10. Gupta JK, Hofmeyr GJ, Smyth R. Position in the second stage of labour for women without epidural anaesthesia. Cochrane Database of Systematic Reviews 2004, Issue 1, Art No: CD002006.DOI: 10.1002/14651858.CD002006.pub2.

11. Lawrence A, Lewis L, Hofmeyr GJ, Styles C. Maternal positions and mobility during first stage labour. Cochrane Database of Systematic Reviews 2013, Issue 10. Art. No.: CD003934. DOI: 10.1002/14651858. CD003934.pub4.

12. Gupta JK, Sood A, Hofmeyr GJ, Vogel JP. Position in the second stage of labour for women without epi- dural anaesthesia. Cochrane Database of Systematic Reviews 2017, Issue 5. Art. No.: CD002006. DOI: 10.1002/14651858.CD002006.pub4.

13. Watson $V$. The duration of the second stage of labour. Modern Midwife 1994;4:21-2.

14. Rahm VA, Hallgren A, Hogberg H, Hurtig I, Odlind V. Plasma oxytocin levels in women during labor with or without epidural analgesia: a prospective study. Acta Obstetricia et Gynecologica Scandinavica 2002;81:1033-9.

15. Goodfellow CF, Hull MG, Swaab DF, Dogterom J, Buijs RM. Oxytocin deficiency at delivery with epidural analgesia. British Journal of Obstetrics and Gynaecology 1983;90(3): 214-9.

16. Kibuka M, Thornton JG. Position in the second stage of labour for women with epidural anaesthesia. Cochrane Database of Systematic Reviews 2017, Issue 2. Art. No.: CD008070. DOI: 10.1002/14651858. CD008070.pub3.

17. Wong CA, Scavone BM, Dugan S, Smith JC, Prather $\mathrm{H}$, Ganchiff JN, et al. Incidence of postpartum lumbosacral spine and lower extremity nerve injuries. Obstet Gynecol 2003;101:279-88

18. Ang CK, Tan TH, Walters WAW, Wood C. Postural influence on maternal capillary oxygen and carbon dioxide tension. British Medical Journal 1969;4(5677):201-3.

19. Humphrey MD, Chang A, Wood EC, Morgan S, Humslow $\mathrm{D}$. The decrease in fetal $\mathrm{pH}$ during the second stage of labour when conducted in the dorsal position. Journal of Obstetrics and Gynaecology of the British Commonwealth 1974;81(8):600-2

20. Scott DB, Kerr MG. Inferior vena caval compression in late pregnancy. Journal of Obstetrics and Gynaecology of the British Commonwealth 1963;70:1044.

21. Russell JGB. The rationale of primitive delivery positions. British Journal of Obstetrics and Gynaecology 1982;89(9): 712-5.

22. Russell JGB. Moulding of the pelvic outlet. Journal of Obstetrics and Gynaecology of the British 
Commonwealth 1969;76(9):817-20.

23. Caldeyro-Barcia R, Noriega-Guerra L, Cibils LA, Alvarez H, Poseiro JJ, Pose SV, et al. Effect of position changes on the intensity and frequency of uterine contractions during labor. American Journal of Obstetrics and Gynecology 1960; 80:284-90.

24. Gupta JK, Glanville JN, Johnson N, Lilford RJ, Dunham RJC, Watters JK. The effect of squatting on pelvic dimensions. European Journal of Obstetrics, Gynecology, and Reproductive Biology 1991;42(1):19-22.

25. Borell U, Fernström I. The movements at the sacroiliac joints and their importance to changes in the pelvic dimensions during parturition. Acta Obstetricia et Gynecologica Scandinavica 1957;36(1):42-57.

26. Gold EM. "Pelvic drive" in obstetrics: an X-ray study of 100 cases. American Journal of Obstetrics and Gynecology 1950;59:890-6.

27. Lilford RJ, Glanville JN, Gupta JK, Shrestha R, Johnson $\mathrm{N}$. The action of squatting in the early postnatal period marginally increases pelvic dimensions. British Journal of Obstetrics and Gynaecology 1989;96(8):964-6.

28. Méndez-Bauer C, Arroyo J, García Ramos C, Menéndez A, Lavilla M, Izquierdo F, et al. Effects of standing position on spontaneous uterine contractility and other aspects of labor. Journal of Perinatal Medicine 1975;3(2):89-100.

29. Simkin P, Ancheta R. The labor progress handbook. Oxford:Blackwell Science, 2005.

30. Ghi T, Farina A, Pedrazzi A, Rizzo N, Pelusi G, Pilu G. Diagnosis of station and rotation of the fetal head in the second stage of labor with intrapartum translabial ultrasound. Ultrasound Obstet Gynecol 2009; 33: 331-336.

31. Myles TD, Santolaya J. Maternal and neonatal outcomes in patients with a prolonged second stage of labor. Obstet Gynecol 2003; 102: 52-58.

32. Yonetani N, Yamamoto R, Murata M, Nakajima E,
Taguchi T, Ishii K. Prediction of time to delivery by transperineal ultrasound in second stage of labor. Ultrasound Obstet Gynecol 2017; 49: 246251. DOI: $10.1002 /$ uog.15944

33. Torkildsen EA, Salvesen KA, Eggebø TM. Prediction of delivery mode with transperineal ultrasound in women with prolonged first stage of labor. Ultrasound Obstet Gynecol 2011; 37: 702-708.

34. Intrapartum transperineal ultrasound for evaluating uterine contraction intensity in the second stage of labor. Muramoto M, Ichizuka1 K, Hasegawa J Nakamura M, Dohi S, Saito H Masaaki Nagatsuka $\mathrm{M}$,

35. American College of Obstetrics and Gynecology Committee on Practice Bulletins-Obstetrics. ACOG Practice Bulletin Number 49, December 2003: Dystocia and augmentation of labor. Obstet Gynecol 2003;102:1445-54.

36. Wilmink FA, Wilms FF, Heydanus R, et al. Fetal complications after placement of an intrauterine pressure catheter: a report of two cases and review of the literature. J Matern Fetal Neonatal Med. 2008;21:880-3

37. Madanes AE, David D, Cetrulo C. Major complications associated with intrauterine pressure monitoring. Obstet Gynecol. 82;59:389-91.

38. Lind BK. Complications caused by extramembranous placement of intrauterine pressure ctheters. Am J Obstet Gynecol. 1999;180:1034-5.

39. Trudinger BJ, Pryse-Davies J. Fetal hazards of the intrauterine pressure catheter: five case reports. BJOG. 1978;85:567-72.

40. Nuttall ID. Perforation of a placental fetal vessel by an intrauterine pressure catheter. BJOG. 1978;85:573-4.

41. Soper DE, Mayhall CG, Dalton HP. Risk factors for intraamniotic infection: a prospective epidemiologic study. Am J Obstet Gynecol. 1989;161:562-8.

42. Harbison L, Bell L. Anaphylactoid syndrome after intrauterine pressure catheter placement. Obstet 
Gynecol. 2010;115:407-8.

43. Bakker JJH, Verhoeven CJM, Janssen PF, et al. Outcomes after internal versus external tocodynamometry for monitoring labor. N Engl J Med. 2010;362:306-13.

44. Chua S, Kurup A, Arulkumaran S, et al. Augmentation of labor: does internal tocography result in better obstetric outcome than external tocography? Obstet Gynecol. 1990;76:164-7.

45. F. Bellussi, L. Alcamisi, G. Guizzardi, D. Parma, G. Pilu. Traditionally vs sonographically coached second stage of labor: a pilot study

46. American College of Obstetrics and Gynecology Committee on Practice Bulletins-Obstetrics. ACOG Practice Bulletin Number 49, December 2003: Dystocia and augmentation of labor.Obstet Gynecol 2003; 102: 1445-1454.

47. Dietz HP, Lanzarone V. Measuring engagement of the fetal head: validity and reproducibility of a new ultrasound technique. Ultrasound Obstet Gynecol 2005; 25: 165-168.

48. Ghi T, Youssef A, Maroni E, Arcangeli T, De Musso F, Bellussi F, Nanni M, Giorgetta F, Morselli-Labate AM, Iammarino MT, Paccapelo A, Cariello L, Rizzo N, Pilu G. Intrapartum transperineal ultrasound assessment of fetal head progression in active second stage of labor and mode of delivery. Ultrasound Obstet Gynecol 2013; 41: 430-435.

49. Ghi T, Contro E, Farina A, Nobile M, Pilu G. Threedimensional ultrasound in monitoring progression of labor: a reproducibility study. Ultrasound Obstet Gynecol 2010; 36: 500-506
50. Molina FS, Terra R, Carrillo MP, Puertas A, Nicolaides $\mathrm{KH}$. What is the most reliable ultrasound parameter for assessment of fetal head descent? UltrasoundObstet Gynecol 2010; 36: 493-499.

51. Ghi T, Maroni E, Youssef A, Morselli-Labate A.M, Paccapelo A, Montoguti E, Rizzo N, Pilu G. Sonographic pattern of fetal head descent: relationship with duration of active second stage of labor and occiput position at delivery .Ultrasound Obstet Gynecol 2014; 44: 82-89

52. Barbera AF, Pombar X, Perugino G, Lezotte DC, Hobbins JC. A new method to assess fetal head descent in labor with transperineal ultrasound. Ultrasound Obstet Gynecol 2009; 33: 313-319

53. Gilboa Y, Frenkel TI, Schlesinger Y, Rousseau S, Hamiel D, Achiron R, Perlman S. Visual Biofeedback using trans-perineal ultrasound during the second stage of labor. Ultrasound Obstet Gynecol. 2017.

54. «What is Biofeedback». Association for Applied Psychophysiology and Biofeedback. 18 May 2008. Retrieved 2015-03-05.

55. Bono, DM, Pastrano, M, Ladonga, PM, Ramirez, A, Laureano, H, Sellote, J Navotas S, Visual Biofeedback: Adjunct Mirror Intervention during Stage Two Labor among Primiparous Women. Asian Journal of Health 2011: 1:204-2016.

Received 29-11-2019

Revised 6-12-2019

Accepted 9-12-2019 